Disclosure of Interest: S. Wind Employee of: Boehringer Ingelheim Pharma GmbH \& Co. KG, G. Simons Employee of: Boehringer Ingelheim Pharma GmbH \& Co. KG, J. Bertulis Employee of: Boehringer Ingelheim Pharma GmbH \& Co. KG, C. Coeck Employee of: Boehringer Ingelheim Pharma GmbH \& Co. KG DOI: 10.1136/annrheumdis-2017-eular.5849

\section{FRI0412 THE POSITIVE EFFECT OF RITUXIMAB IN PULMONARY FIBROSIS OF SYSTEMIC SCLEROSIS}

P. Kiryttopoulos ${ }^{1}$, T. Michailidis $^{1}$, E. Papchianou ${ }^{1}$, M. Charalampidis ${ }^{2}$ P. Dimitriadis ${ }^{3}$, A. Agorastos ${ }^{4} .{ }^{1}$ Department of Internal Medicine, General Hospital of Veria, Veria; ${ }^{2}$ Gastroenterology Department, Theageneio Hospital of Thessaloniki, Thessaloniki; ${ }^{3}$ Health Center of Alexandria, Alexandria, Greece;

${ }^{4}$ Oncology Department, St. Thomas Hospital, London, United Kingdom

Background: Pulmonary fibrosis is one of the gravest manifestations of Systemic Sclerosis (SSc) and conventional DMARDs therapy has not shown any particular positive effect.

Objectives: Our goal was to see whether the elimination pf B - lymphocytes through use of anti-CD20 Mab, Rituximab (RTX) would offer to the improvement of the pulmonary function of SSc patients.

Methods: We studied 23 SSc patients with pulmonary fibrosis, who received treatment with RTX $(n=12)$ or DMARDs treatment $(n=11)$ for 1 to 3 years (1,9 years). Conventional therapy included azathioprine $(n=4)$, mycophenalate $(n=6)$ and methotrexate $(n=2)$. RTX - treated patients were recorded with FVC improvement in the first year of treatment (FVC $81,3+$ +/ 12,6 vs FVC 87,4 +/11,3 out on the onset of the study and at the first year respectively, $p=0,02$ ) when on the other hand DMARDs treated patients didn't show any FVC improvement at all.

Results: All RTX - treated patients did not present any lung HRCT deterioration imaging, in contrast to DMARDs - treated patients who were also submitted to lung HRCT each year of the study, all showing signs of CT imaging deterioration. Similar findings, as far as FVC was concerned, were recorded at the 3rd year of the study (RTX patients, $n=6$ and DMARDs patients, $n=11$ ). 3rd year RTX FVC was $92,6+/-13,2$ vs $80,7+/-11,8$ at the onset of the study, $p=0,04$ when DMARDs treated patients were all presented with worst 3rd year FVC compared to their primary FVC, $p<0,01$

Conclusions: Our small cohort of SSc patients with pulmonary fibrosis shows that it is possible that rituximab may be proven helpful to at least prevent the deterioration of the interstitial pulmonary fibrosis of Systemic Sclerosis. The pathophysiology of this particular fibrosis and the possible molecular role of B-lymphocytes in the inversion of this procedure need yet to be furtherly explored. Disclosure of Interest: None declared

DOI: 10.1136/annrheumdis-2017-eular.6398

\section{FRI0413 ACUTE EFFECT OF ILOPROST ON PERIPHERAL CIRCULATION AS ASSESSED BY VIDEOCAPILLAROSCOPY AND 22-MHZ POWER DOPPLER ULTRASONOGRAPHY}

T. Schioppo ${ }^{1,2}$, A. Orenti ${ }^{1,3}$, P. Boracchi ${ }^{1,3}$, O. De Lucia $^{2}$, A. Murgo ${ }^{2}$,

P.L. Meroni ${ }^{1,2}, \mathrm{~F}$. Ingegnoli ${ }^{1,2}$ on behalf of OPERA study group. ${ }^{1}$ Università degli Studi di Milano; ${ }^{2}$ ASST Pini-CTO; ${ }^{3}$ Lab of Medical Statistics, Epidemiology and Biometry GA Maccacaro, Milan, Italy

Background: Vascular involvement is a hallmark of systemic sclerosis (SSc) and it is responsible for some of the most common complications of the disease such as Raynaud's phenomenon (Rp), digital ulcers (DUs) and pulmonary arterial hypertension. I.V. iloprost (ILO), a prostacyclin analogue, has been shown to be effective in reducing Rp severity, DUs healing and preventing [1].

Objectives: To assess the acute effect of ILO on acral circulation as assessed by nailfold videocapillaroscopy (NVC) and 22-MHz Power Doppler ultrasound (PDUS).

Methods: 44 SSc consecutive patients fulfilling the 2013 EULAR classification criteria were enrolled. Each patient was evaluated before and immediately after I.V. ILO administration $(0.5-2.0 \mathrm{ng} / \mathrm{Kg} / \mathrm{min}$ for 6 consecutive hours). PDUS was performed at the 3rd and 4th finger of the dominant hand after exclusion of ulnar artery occlusion (UAO). In case of UAO non-dominant hand was examined. Ultrasound investigation was performed with Esaote MyLab 70 XVG by means of linear array transducer $(10-22 \mathrm{MHz})$. Power Doppler settings were standardized (Doppler frequency $14.3 \mathrm{MHz}$, Gain 55\%, PRF $750 \mathrm{~Hz}$ ). PDUS measurements included sagittal scan of nailbed and fingertip qualitatively graded from 1 (no signal) to 4 (marked hyperemia) [2], and resistivity index (RI) of ulnar and radial proper digital arteries. Capillary width (sum of capillary width/mm) was calculated by NVC with magnification 200X performed on two images of the same digits examined by PDUS.

Results: The study population included 44 SSc patients, 40 (90.9\%) women, 35 $(79.5 \%)$ limited cutaneous SSc, median age 60.2 years old and median disease duration 8 years. $19(43.2 \%)$ had history of DUs, among them 15 had experienced more than one DUs and 1 had active DU at the moment of evaluation.

Semiquantitative perfusion score of sagittal scan of nailbed and fingertip pre- and post-therapy are shown in Table 1.

Changes in RI and capillary width pre- and post-infusion are reported in Table 2. Conclusions: A statistically significant post-infusion rise in RI, fingertip and

\begin{tabular}{|c|c|c|c|c|c|}
\hline & \multicolumn{2}{|c|}{ Pre-infusion } & \multicolumn{2}{|c|}{ Post-infusion } & \multirow[t]{2}{*}{ OR $(95 \% \mathrm{Cl})$} \\
\hline & $\%$ & Cumulate $\%$ & $\%$ & Cumulate $\%$ & \\
\hline Fingertip PDUS & & & & & $4.21(2.12-8.35)$ \\
\hline Grade 1 & 29.55 & 29.55 & 14.77 & 14.77 & $p$-value $<0.001$ \\
\hline Grade 2 & 22.73 & 52.28 & 15.91 & 30.68 & \\
\hline Grade 3 & 12.50 & 64.78 & 12.50 & 43.18 & \\
\hline Grade 4 & 35.23 & 100 & 56.82 & 100 & \\
\hline Nailbed PDUS & & & & & $8.96(4.15-19.32)$ \\
\hline Grade 1 & 17.05 & 17.05 & 6.82 & 6.82 & $p$-value $<0.001$ \\
\hline Grade 2 & 34.09 & 51.14 & 13.64 & 20.46 & \\
\hline Grade 3 & 18.18 & 69.32 & 14.77 & 35.23 & \\
\hline Grade 4 & 30.68 & 100 & 64.77 & 100 & \\
\hline
\end{tabular}

Table 2

\begin{tabular}{lccc}
\hline & Pre-infusion & Post-infusion & Mean difference $(95 \% \mathrm{Cl})$ \\
\hline Resistivity index & 0.773 & 0.794 & $0.021(0.005,0.037)$ \\
Capillary width & 247.5 & 257.9 & $\begin{array}{c}p \text {-value }=0.0122 \\
\end{array}$ \\
& & & $p$-value $=0.1077$ \\
\hline
\end{tabular}

nailbed PDUS grade were found. Capillary width was also increased, but it was not statistically significant. As such, these novel results indicate that ILO, alongside its clinical effect, is able to enhance vascularization even at the most peripheral levels.

References:

[1] Pope J et al. Cochrane Database Syst Rev. 2000;(2):CD000953.

[2] Newman JS et al. Radiology. 1996,198:582-584.

Disclosure of Interest: None declared

DOI: 10.1136/annrheumdis-2017-eular.3849

\section{FRI0414 CAN ECHOCARDIOGRAPHY REPLACE FOLLOW-UP CARDIAC CATHETERIZATION IN RE-EVALUATION OF PULMONARY ARTERIAL HYPERTENSION? A LONGITUDINAL SINGLE-CENTER STUDY OF 30 CONNECTIVE TISSUE DISEASE PATIENTS}

V.-K. Bournia ${ }^{1}$, I. Tsangaris $^{2}$, L. Rallidis ${ }^{2}$, D. Konstantonis ${ }^{2}$, A. Anthi ${ }^{2}$, S. Orfanos ${ }^{2}$, S. Panopoulos ${ }^{1}$, P.P. Sfikakis ${ }^{1} .{ }^{1}$ First Department of Propedeutic Internal Medicine and Joined Rheumatology Program; ${ }^{2}$ Pulmonary Hypertension Clinic, Attikon University General Hospital, Medical School, National and Kapodistrian University of Athens, Athens, Greece

Background: Transthoracic echocardiography (TTE) is well validated for initial assessment of connective tissue disease patients with suspected pulmonary arterial hypertension $(\mathrm{PAH})$. However, in patients with $\mathrm{PAH}$ confirmed by the gold-standard method of right heart catheterization $(\mathrm{RHC})$ the role of TTE in their follow-up is less known.

Objectives: To test the hypothesis that TTE can replace follow-up RHC in connective tissue disease-associated PAH.

Methods: This retrospective study included 30 consecutive patients with systemic sclerosis $(n=24)$ and mixed connective tissue disease $(n=6)$ (mean age $\pm S D: 60 \pm 12$ years, $87 \%$ women), in whom PAH was suggested by TTE and further confirmed by a baseline RHC [pulmonary artery systolic pressure (PASP): $56.8 \pm 19.1$, range $25-90 \mathrm{mmHg}$; pulmonary vascular resistance $(\mathrm{PVR})$ : $5.9 \pm 3.8$, range $0.7-$ 14.5 Wood units; cardiac output: $4.4 \pm 1.3$, range $2-7.8 \mathrm{~L} / \mathrm{min})$. All 30 patients underwent a second RHC and TTE at follow-up, after 11 \pm 6 (range 4-29) months. Ten patients had a 3rd follow-up RHC and TTE 22 7 (range 15-37) months from baseline, thus producing in all 50 pairs of baseline and follow-up measurements. By considering follow-up RHC as the gold-standard, we examined whether clinically meaningful hemodynamic changes (i.e. $>15 \%$ change from baseline) in either RHC-derived PASP or PVR could be predicted by the corresponding changes from baseline in follow-up TTE. RHC and TTE were always performed, each, by the same examiner.

Results: In $68 \%$ of comparisons between baseline and follow-up, the latter TTE measurements could safely replace RHC in terms of PASP estimation. Using Mc Nemars test we confirmed that the two methods did not differ significantly (Table 1). When in addition to changes in PASP, PVR changes were also considered, follow-up TTE could again safely replace the second RHC in $70 \%$ patient retests (Table 2). Of note, baseline hemodynamic values or TTE measurements did not differ between patients in whom TTE could replace RHC and those in whom the results of the two methods at follow-up were divergent.

Table 1. McNemars test comparing PASP estimated by repeat TTE to that measured by repeat $\mathrm{RHC}$ shows no difference between the two methods

\begin{tabular}{lcc}
\hline Repeat TTE & \multicolumn{2}{c}{ Repeat RHC } \\
\cline { 2 - 3 } & Stable or improved PASP & Deteriorated PASP $(>15 \%)$ \\
\hline Stable or improved PASP & 25 & 9 \\
Deteriorated PASP $(>15 \%)$ & 7 & 9 \\
\hline
\end{tabular}

$\mathrm{P}=\mathrm{NS}$ (0.8).

Conclusions: In a study where operator-dependent methodological errors are limited we found that the majority of connective tissue disease patients with $\mathrm{PAH}$ 
Table 2. McNemars test comparing PASP estimated by repeat TTE to hemodynamic parameters measured by repeat $\mathrm{RHC}$ when PVR is also considered

\begin{tabular}{lcc}
\hline Repeat TTE & \multicolumn{2}{c}{ Repeat RHC } \\
\cline { 2 - 3 } & $\begin{array}{c}\text { Stable or improved PASP } \\
\text { and PVR }\end{array}$ & $\begin{array}{c}\text { Deteriorated PASP or PVR }(>15 \%) \\
\text { or PVR }(>15 \%)\end{array}$ \\
\hline Stable or improved PASP & 24 & 10 \\
Deteriorated PASP $(>15 \%)$ & 5 & 11 \\
\hline
\end{tabular}

$\mathrm{P}=\mathrm{NS}$ (0.3).

can be safely monitored in the long-term by TTE. Further studies to help identify those patients at need for follow-up RHC are warranted.

Disclosure of Interest: None declared

DOI: 10.1136/annrheumdis-2017-eular.2204

\section{FRI0415 CAPILLAROSCOPIC ABNORMALITIES CORRELATE WITH ORGAN DAMAGE IN CHINESE PATIENTS WITH SYSTEMIC SCLEROSIS}

W.Y. Yeung ${ }^{1}$, C.C. Mok ${ }^{2}$, K.L. Lee ${ }^{1} .{ }^{1}$ Department of Medicine, Pamela Youde Nethersole Eastern Hospital; ${ }^{2}$ Department of Medicine, Tuen Mun Hospital, Hong Kong,

Objectives: To study the nailfold capillaroscopic patterns and microangiopathy evolution score (MES) and correlate with the severity of organ damage in Chinese patients with systemic sclerosis (SSc)

Methods: Patients who fulfilled the 2013 ACR criteria for SSc were studied. A full physical examination was performed. Blood was taken for SSc autoantibodies, along with a full lung function test and echocardiogram. The extent of skin involvement was assessed by the modified Rodnan skin score (mRSS). Organ damage of SSc was assessed by the Medsger disease severity scale. A Nailfold capillaroscopic examination was performed by a trained nurse blinded to the medical history of the patients. The following parameters were obtained: (1) capillaroscopy patterns (early, active and late); (2) Degree of enlarged capillaries, giant capillaries, capillary haemorrhages, capillary density, disorganization of vascular array and capillary ramification assessed by a semi-quantitative method; and (3) MES score (sum of capillary density, disorganization of vascular array and capillary ramification). Correlation among the capillaroscopic patterns, individual capillaroscopic parameters and the MES with organ damage was performed by the Spearman's rank correlation test.

Results: A total of 138 Chinese patients were studied ( $91.3 \%$ women; age $56.36 \pm 11.81$ years). The median disease duration was $8.14 \pm 6.21$ years. 39 $(28.3 \%)$ patients had DcSSc and $99(71.7 \%)$ had LcSSc. Anti-centromere, anti-Scl 70 and anti-RNA polymerase III antibodies were present in $28.6 \%, 28.5 \%$ and $5.6 \%$ of the patients respectively. Organ damage was present in all patients, most common being skin $(84 \%)$, lung $(79 \%)$, peripheral vascular $(74 \%)$ and Gl tract (46\%). The median mRSS was 6 (IQR $2-12)$. A total of 27 patients $(19.7 \%)$ had early SSc pattern on capillaroscopy, $40(29.2 \%)$ had active pattern and $68(49.6 \%)$ had late pattern. The median MES score was 3.02 (IQR 1.76-5.25). Patients with late SSc pattern on capillaroscopy had significantly longer disease duration and were more likely to have organ damage in the general, peripheral vascular and lung domains compared to those not having late SSc patterns. The total MES score correlated significantly with organ damage scores in the muscle (Rho 0.188; $\mathrm{p}=0.029$ ), $\mathrm{Gl}$ tract (Rho 0.169; $\mathrm{p}=0.048$ ) and lung (Rho $0.265 ; \mathrm{p}=0.006$ ) domains. Regarding individual components of the MES score, capillary density correlated significantly with scores in the peripheral vascular (Rho 0.460; $<<0.001$ ), skin (Rho $0.343 ; p<0.001$ ), joint/tendon (Rho 0.220; $p=0.011$ ), muscle (Rho 0.295; $p=0.001$ ), Gl tract (Rho 0.188; $p=0.028$ ) and lung (Rho $0.238 ; p=0.015)$ damage domains. Enlarged capillaries correlated significantly with scores in the muscles (Rho $-0.205 ; p=0.017$ ) and lung (Rho -0.213; $p=0.029$ ) damage domains. Giant capillaries and microhaemorrhages correlated significantly with scores in the peripheral vascular (Rho 0.239; $\mathrm{p}=0.005$ and Rho $0.228 ; \mathrm{p}=0.007$ respectively) damage domains. Disorganization of capillary array correlated significantly with scores in the lung (Rho 0.253; $p=0.009$ ) damage domain. Capillary ramifications correlated significantly with the scores in the kidney (Rho $0.171 ; p=0.048$ ) damage domains. Conclusions: In Chinese patients with SSc, capillaroscopic patterns and components of the microangiopathy evolution score were associated with severity of organ damage.

Disclosure of Interest: None declared

DOI: 10.1136/annrheumdis-2017-eular.2020

\section{FRI0416 CHARACTERISTICS AND CAPILLAROSCOPIC FINDINGS OF SYSTEMIC SCLEROSIS PATIENTS WITH SEVERE PERIPHERAL VASCULAR INVOLVEMENT RECEIVING SPECIFIC VASODILATOR TREATMENT}

Y. Yalçınkaya, A.U. Ünal, Z. Ertürk, U. Gazel, S. Kaymaz, A. Aksoy,

P. Atagündüz, N. İnanç, H. Direskeneli. Department of Internal Medicine, Division of Rheumatology, Marmara University, School of Medicine, Istanbul, Turkey

Background: Severity of peripheral vascular involvement (PVI)is known as an important determinig cause of morbidity in sytemic sclerosis (SSc). Different vasodilating agents have been found to reduce severity and contribute to healing of digital ulcers (DU)in SSc.
Objectives: We aimed to evaluate the characteristics and capillaroscopic patterns of the patients with severe PVI under different vasodilator therapeutic regimens. Methods: The patients were grouped as "severe PVI" if score of $\mathrm{PVI}$ is $\geq 2$ (PVT=2, digital pitting scars; PVT=3, digital tip ulcerations and PVT=4, digital gangrene; Medsger) and "non-severe PVI" if score of $\mathrm{PVI}$ is $\leq 1$ ( $\mathrm{PVI}=0$, no Raynaud's; $P V I=1$, Raynaud's requiring vasodilators). We included patients with severe PVI who received cyclic iloprost and bosentan and/or sildenafil and compared to non-severe PVI. Nail fold video-capillaroscopy (NVC)was assessed qualitatively (Cutalo et al., early, active and late patterns).

Results: Severe PVI group more frequently had diffuse cutaneous form, contractures, lung disease, anti-Scl70 positivity and high acute phase response and exposed to immunosuppressives (table-1).

Table 1. Demographics and characteristics of SSc Patients

\begin{tabular}{lccc}
\hline & $\begin{array}{c}\text { Non-severe PVI } \\
\mathrm{n}=32\end{array}$ & $\begin{array}{c}\text { Severe PVI group } 2 \\
\mathrm{n}=22\end{array}$ & $\mathrm{p}$ \\
\hline Age (year)/female (\%) & $44 \pm 15 / 88 \%$ & $48 \pm 12 / 87 \%$ & $\mathrm{NS}$ \\
Duration of Raynaud's/nonRaynaud's (year) & $9 \pm 9 / 5 \pm 5$ & $12 \pm 10 / 9 \pm 9$ & $\mathrm{NS}$ \\
Diffuse Cutaneous involvement & $5(16 \%)$ & $10(45 \%)$ & $\mathrm{P}=0,039$ \\
Anti-Scl70 (+) & $7(22 \%)$ & $11(50 \%)$ & $\mathrm{P}=0,024$ \\
Interstitial lung disease & $7(22 \%)$ & $14(64 \%)$ & $\mathrm{P}=0,001$ \\
Flexion contractures & $3(9 \%)$ & $10(45 \%)$ & $\mathrm{P}=0,008$ \\
Echo PAP $>40$ mmHg & $2(6 \%)$ & $4(18 \%)$ & $\mathrm{NS}$ \\
High acute phase response & $12(38 \%)$ & $18(82 \%)$ & $\mathrm{P}=0,002$ \\
FVC $\leq 80 \% /$ & $3(9 \%)$ & $12(55 \%)$ & $\mathrm{P}<0,001$ \\
DLCO $\leq 80 \%$ & $10(31 \%)$ & $14(64 \%)$ & $\mathrm{P}=0,011$ \\
Immunosuppressives- CYC (pulse) & $5(16 \%)$ & $9(41 \%)$ & $\mathrm{P}=0,018$ \\
- Azathioprin & $8(25 \%)$ & $10(46 \%)$ & $\mathrm{P}=0,030$ \\
- Mycphenolate mofetil & $2(6 \%)$ & $10(46 \%)$ & $\mathrm{P}<0,001$ \\
- Rituksimab & $1(3 \%)$ & $6(27 \%)$ & $\mathrm{P}=0,027$ \\
- Steroids (PRD $<10$ mg/d) & $11(34 \%)$ & $17(77 \%)$ & $\mathrm{P}=0,001$ \\
\hline
\end{tabular}

NS $=$ not significant

Scores of telangiectasia, skin, activity and severity were lower in non-severe group. NVC late pattern was frequent and early pattern was rare in severe PVI groups. Forty-one\% (9/22) of patients received second oral agent for PVI. Monotherapy and combination groups had similar scores (table-2).

\begin{tabular}{|c|c|c|c|c|}
\hline & $\begin{array}{c}\text { non-severe } \\
\text { PVI } \\
\text { n=32 }\end{array}$ & $\begin{array}{c}\text { severe } \\
\text { PVI } \\
\mathrm{n}=22\end{array}$ & $\begin{array}{c}\text { Cyclic iloprostt } \\
\text { bosentan } \\
n=10\end{array}$ & $\begin{array}{c}\begin{array}{c}\text { Cyclic iloprost } \\
\text { bosentan+sildenafi } \\
n=9\end{array} \\
\text { a }\end{array}$ \\
\hline NVC-normal & $3(9 \%)$ & 0 & 0 & 0 \\
\hline early pattern & $12(38 \%)^{* *}$ & $2(9 \%)$ & $1(10 \%)$ & $1(11 \%)$ \\
\hline -active pattern & $10(31 \%)$ & $2(9 \%)$ & $2(20 \%)$ & $0(0 \%)$ \\
\hline -late pattern & $8(25 \%)$ & $18(82 \%)^{*}$ & $7(70 \%)$ & $8(89 \%)$ \\
\hline Telangiectasia score (Shah) & $3,7 \pm 2,5 * *$ & $6 \pm 3,7$ & $4,8 \pm 3,2$ & $7,1 \pm 4,2$ \\
\hline Modified Rodnan skin score & $5,8 \pm 5^{*}$ & $13,5 \pm 8,7$ & $13,6 \pm 9,3$ & $13,2 \pm 7,6$ \\
\hline Activity score (Valentini) & $0,9 \pm 0,9^{*}$ & $2,1=1,2$ & $2,2 \pm 1,3$ & $2,2 \pm 1,2$ \\
\hline Severity score (Medsger) & $3,5 \pm 1,7 *$ & $7,5 \pm 2,4$ & $7,8 \pm 2,3$ & $7,4 \pm 2,7$ \\
\hline
\end{tabular}

Conclusions: NVC late pattern was frequent in severe PVI group with long disease duration, exposed to intensive immunosuppresives and received specific vasodilators for PVI. Disease activity and severity were higher in severe PVI group. One third of the severe group required oral combination therapy for PVI. Monotherapy and combination groups were similar in terms of severity. NVC is a useful method to monitor digital ischemia and severe organ involvement in SSc.

Disclosure of Interest: None declared

DOI: 10.1136/annrheumdis-2017-eular.3584

\section{FRI0417 EXERCISE-INDUCED PULMONARY HYPERTENSION IN SYSTEMIC SCLEROSIS PATIENTS: TRANSCRIPTOME ANALYSIS OF PERIPHERAL BLOOD AT THE EARLY STAGE OF THE DISEASE}

Y. Koyama ${ }^{1}$, S. Fuke ${ }^{2}$, Y. Sato ${ }^{3}$, T. Higuchi ${ }^{1} .{ }^{1}$ Center for Autoimmune Diseases, Division of Rheumatology; ${ }^{2}$ Division of Cardiology, Japanese Red Cross Okayama Hospital, Okayama; ${ }^{3}$ DNA Chip Research Inc., Tokyo, Japan

Background: Pulmonary arterial hypertension $(\mathrm{PAH})$ is prominent as a vascular involvement in systemic sclerosis (SSc), which remains a leading cause of death in spite of current best treatments. As the pulmonary vascular disease (PVD) can be well compensated for, more than a half of the pulmonary circulation is impaired before early $\mathrm{PAH}$ is detected. Although recent studies focused on molecular basis of the PVD, the underlying mechanisms have not been fully elucidated, especially at the early stage of the disease.

Objectives: To detect the subclinical PVD, and to explore the changes in transcriptome of peripheral blood at the early stage of SSc associated PAH. Methods: Total of 74 cases without PAH symptoms (NYHA I) with either Raynaud phenomenon (RP: $n=61$ ), skin sclerosis $(n=43)$ or SSc-related autoantibody (anti-RNP: $n=10$, centromere: $n=36$, topoisomerase-1: $n=2$, RNA polymerase III: $\mathrm{n}=2$ ) were enrolled. To detect the latent $\mathrm{PAH}$, exercise Doppler echocardiography (DE) with Master's two-step stress was carried out. Systolic PAP (SPAP) was determined by maximum velocities of tricuspid regurgitation jets, and exercise induced pulmonary hypertension (exPH) group was segregated from normal response group (exN) with using the definition of a SPAP greater than $40 \mathrm{~mm}$ $\mathrm{Hg}$ during exercise, or a exercise increase in SPAP by greater than $20 \mathrm{~mm}$ 